\title{
Mule Deer Responses to Deer Guards
}

\section{DALE F. REED, THOMAS M. POJAR, AND THOMAS N. WOODARD}

Highlight: In this investigation the effectiveness of guards 12,18, and 24 feet long in preventing mule deer from crossing vehicle openings in fences 8 feet high was evaluated. The guards were constructed of flat mill steel rails $1 / 2 \times 4 \times 120$ inches, and were tested under both controlled and field conditions. Under controlled tests, 16 of 18 deer successfully crossed the guard. Fifteen deer and one elk crossed guards under field conditions. Deer did not attempt wide jumps over the guards, but rather walked, trotted, or bounded across them. Use of this guard type under the condition tested is not recommended.

Fences $8 \mathrm{ft}$ in height are frequently installed along primary highways where the possibility of collision between vehicles and mule deer (Odocoileus hemionus hemionus) is high. They are also established along perimeters of big game exclosures and enclosures. While these fences prevent many animals from going where not desired, a problem arises when it is necessary to permit vehicle access through the fences. When gates hinder vehicular traffic flow, structures such as modified cattle guards have been used and recommended. The physical requirements of guards to preclude deer or elk (Cervus canadensis) crossings have not been tested and neither deer nor elk responses to such structures have been documented.

The purpose of this investigation was to evaluate the effectiveness of three lengths of guards in preventing deer from

The authors are wild life researcher, assistant wildlife researcher, and senior research tech nician, Colorado Division of Wildlife, Glenwood Springs.

Research was supported by Federal Aid to Wild life Restoration Project W-38-R.

The Bureau of Land Management, Glenwood Springs office, provided field assistance. The Colorado Division of Highways installed the Avon deer guard. Dr. Lee E. Yeager and Harold M. Swope critically reviewed this paper, herewith acknowledged with appreciation.

Manuscript received September 5, 1973. crossing through vehicle openings in $8-\mathrm{ft}$ fences.

\section{Methods and Materials}

Two deer guards were installed in 8 -ft fences, one adjacent to Interstate 70 near Avon, Colo., and the other in a Bureau of
Land Management wildlife exclosure fence at Trail Gulch between Dotsero and Burns, Colo. Both guards utilized $10 x$ $12 \mathrm{ft}$ sections (Fig. 1) constructed with flat mill steel $1 / 2 \times 4 \times 120$-inch (width, height, and length, respectively). The flat mill steel rails were perpendicular to the direction of traffic. The lengths of guard tested, 12,18 , and $24 \mathrm{ft}$, were measured parallel to the direction of traffic flow. The guard at Trail Gulch was used for controlled tests, while both were monitored for deer use under field conditions.

\section{Controlled Conditions}

The Trail Gulch guard was constructed with two $10 \times 12$-ft sections for a total

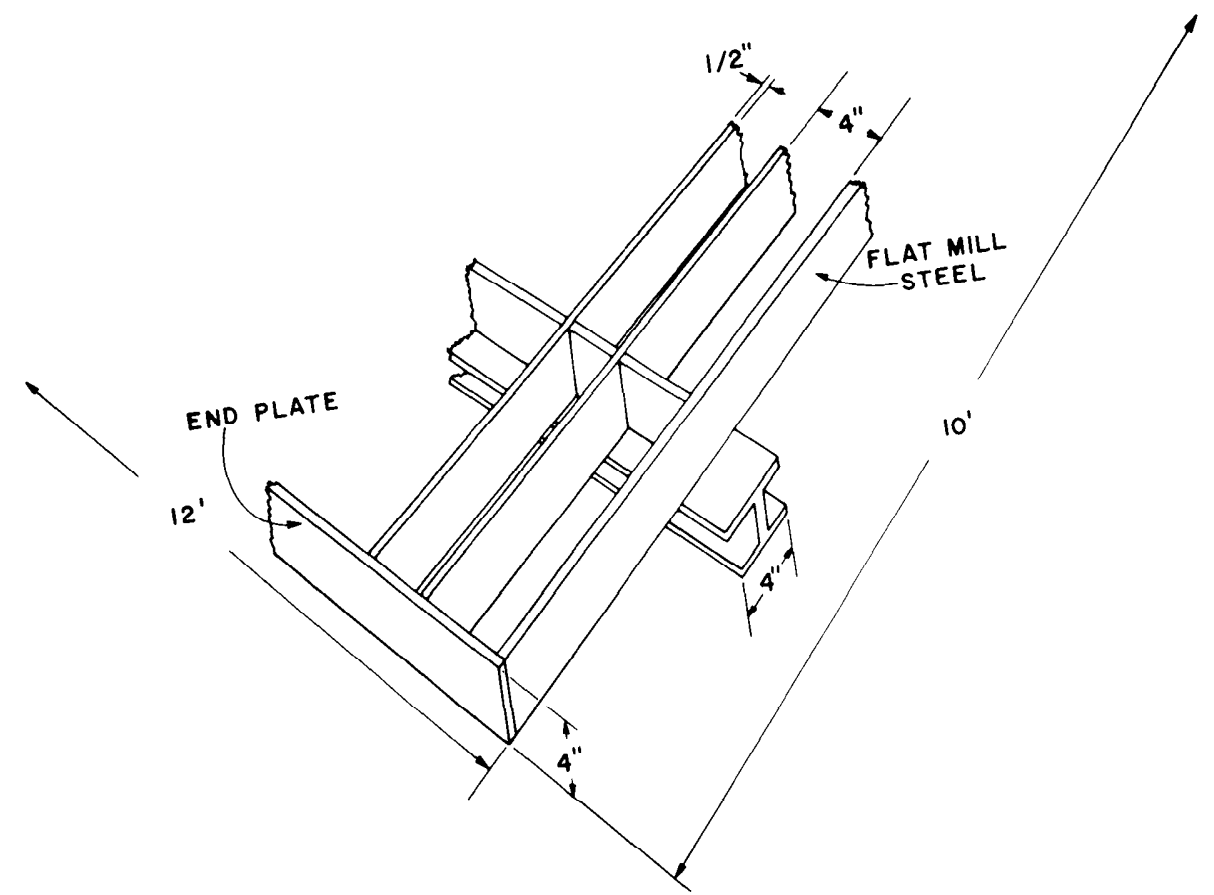

Fig. 1. Modified deer-cattle guard specifications. 
Table 1. Responses of 16 mule deer to deer guards of 12,18 , and $24 \mathrm{ft}$ at Trail Gulch.

\begin{tabular}{|c|c|c|c|c|c|c|c|}
\hline Number & $\begin{array}{l}\text { Length of } \\
\text { guard }(\mathrm{ft})\end{array}$ & $\begin{array}{l}\text { Time from release } \\
\text { to completed } \\
\text { crossing }(\mathrm{sec})\end{array}$ & $\begin{array}{l}\text { Number of } \\
\text { approaches }^{1}\end{array}$ & $\begin{array}{c}\text { Number of } \\
\text { investigative } \\
\text { instances }^{2}\end{array}$ & $\begin{array}{l}\text { Distance covered } \\
\text { in first step or } \\
\text { bound }(\mathrm{ft})\end{array}$ & $\begin{array}{l}\text { Predominant } \\
\text { mode of crossing }\end{array}$ & Sex/age ${ }^{3}$ \\
\hline 1 & 12 & 110 & 3 & - & - & trot & $\mathrm{F} / \mathrm{F}$ \\
\hline 2 & 12 & 375 & 1 & 4 & 3.90 & walk & $\mathrm{F} /$ \\
\hline 3 & 12 & 11 & 0 & 0 & 7.94 & bound & $\mathrm{F} /$ \\
\hline 4 & 12 & 15 & 1 & 1 & - & walk & $\mathrm{F} /$ \\
\hline 5 & 12 & 16 & 0 & 0 & 3.54 & walk & $\mathrm{F} /$ \\
\hline 6 & 12 & 60 & 0 & 0 & 1.90 & walk & $\mathrm{M} /$ \\
\hline 7 & 12 & 584 & 5 & 7 & 7.64 & bound & $\mathrm{M} / \mathrm{F}$ \\
\hline 8 & 12 & 37 & 1 & 3 & 5.28 & trot & $\mathrm{M} /$ \\
\hline 9 & 12 & 95 & 1 & 4 & 6.00 & bound & $\mathrm{M} /$ \\
\hline 10 & 18 & 27 & 0 & 2 & 3.61 & trot & $\mathrm{F} /$ \\
\hline 11 & 18 & 16 & 0 & 1 & 3.21 & trot & $\mathrm{M} /$ \\
\hline 12 & 18 & 1,017 & 197 & 16 & 3.67 & walk & $\mathrm{M} / \mathrm{F}$ \\
\hline 13 & 18 & 70 & 0 & 0 & 1.57 & walk & $\mathrm{M} / \mathrm{F}$ \\
\hline 14 & 18 & 217 & 6 & 9 & 6.59 & bound & $\mathrm{F} / \mathrm{T}$ \\
\hline 15 & 24 & 84 & 2 & 3 & 2.66 & trot & $\mathrm{F} /$ \\
\hline 16 & 24 & 27 & 0 & 0 & 6.33 & bound & $\mathrm{F} / \mathrm{F}$ \\
\hline
\end{tabular}

${ }^{1}$ Deer moved to guard as if to cross, then turned away.

${ }^{2}$ Refers to instances of investigative behavior (Scott, 1956) where the animal visibly made a sensory inspection by bending neck, moving ears forward, and looking at guard.

${ }^{3}$ Male or female is indicated by $\mathrm{M}$ or $\mathrm{F}$ before slash (/), Fawn is indicated by $\mathrm{F}$ after slash. All others were either yearling or mature.

length of $24 \mathrm{ft}$. A runway $10 \mathrm{ft}$ wide and $59 \mathrm{ft}$ long was constructed with 8 -ft fencing at one approach to the guard.

To test a $12-\mathrm{ft}$ guard, half of the $24-\mathrm{ft}$ guard was covered with plywood and 2-3 inches of soil. To test $18-\mathrm{ft}$ and $24-\mathrm{ft}$ guards plywood sections were removed. The tests were handled in the same manner for all guard lengths.

The tests involved releasing deer in the runway and observing their response as they attempted to escape via their only exit across the guard. Each deer was released from an individual carrying crate (Bartmann and Steinert, 1970) as quietly as possible. The observer opened the crate, released the deer, then remained motionless until the animal crossed the guard. The time from release to complete guard crossing was measured with a stop watch. Other observations were noted mentally and recorded immediately after each test.

Eighteen deer of varying ages and both sexes were obtained from a winter trapping program. Ten of these animals were tested with the 12 -ft guard, six with the 18 -ft guard, and two with the 24 -ft guard.

\section{Field Conditions}

The guard near Avon was $20 \mathrm{ft}$ wide and $12 \mathrm{ft}$ long. The Trail Gulch guard, except for 2 months during which the controlled tests were conducted, was 10 $\mathrm{ft}$ wide and $24 \mathrm{ft}$ long. Periodic track counts were made on both approaches to the guards, and the guard rails were examined from October 6, 1972, to December 31, 1972, at Avon and from June 29, 1972, to April 19, 1973, at Trail Gulch. Any crossings or attempts to jump the guard were determined by closely examining the road for tracks and the guard rails for hoof scuff marks and deer hair.

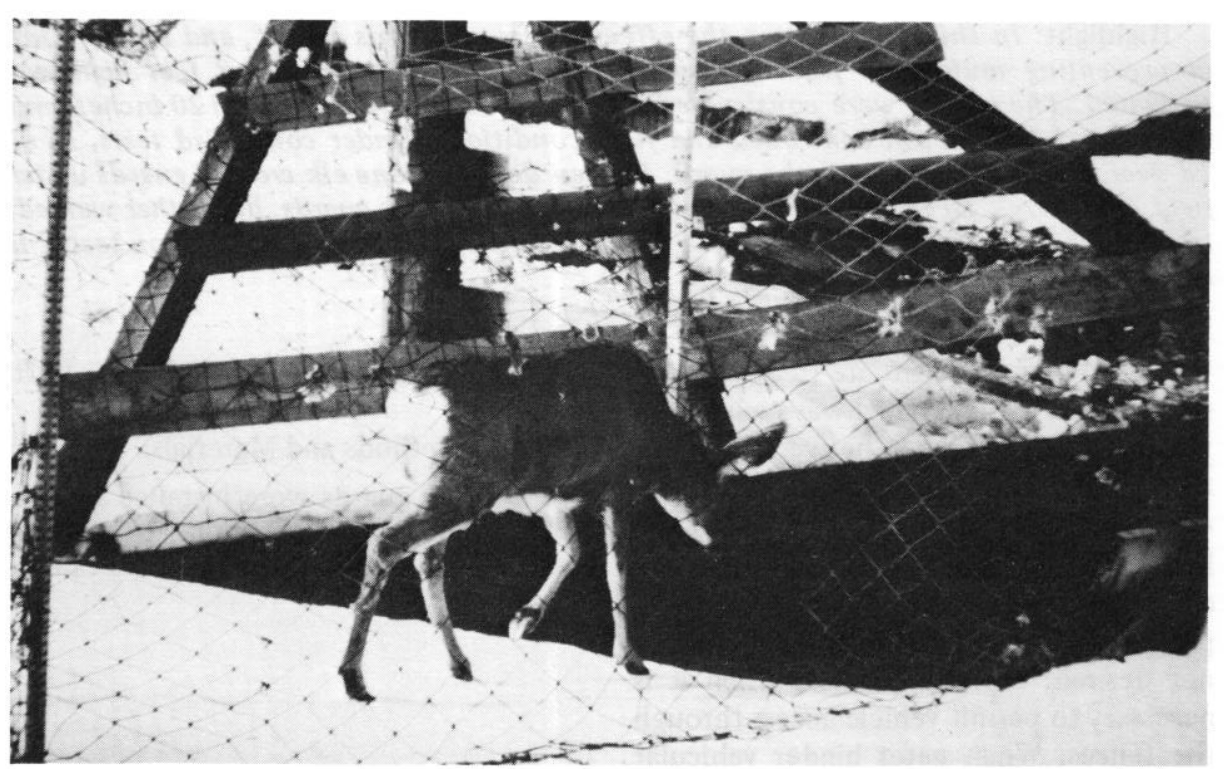

Fig. 2. Test deer Number 15 spent 84 seconds from release to having completed a crossing of the guard. During this time the animal completed three instances of investigative behavior, one of which is shown.

Table 2. Number of deer and elk crossings and number of tracks recorded during the field evaluations of the Avon and Trail Gulch deer guards.

\begin{tabular}{lccccc}
\hline \hline Guard & Species & $\begin{array}{c}\text { Number of } \\
\text { crossings }\end{array}$ & $\begin{array}{c}\text { Tracks when } \\
\text { crossing }^{1}\end{array}$ & $\begin{array}{c}\text { Tracks when } \\
\text { no crossings }^{2}\end{array}$ & $\begin{array}{c}\text { Minimum } \\
\text { number } \\
\text { crossings } \\
\text { prevented }^{3}\end{array}$ \\
\hline Avon & deer & 4 & 76 & 64 & 6 \\
Trail Gulch & deer & 11 & 94 & 151 & 5 \\
Total & elk & 1 & 2 & 4 & 3 \\
\hline
\end{tabular}

${ }^{1}$ The number of tracks at both ends of the guard when crossings occurred.

${ }^{2}$ The number of tracks at both ends of the guard when no crossings were detected. Animals making tracks appeared to have been prevented from crossing the guards.

${ }^{3}$ The number of days when at least one deer or elk made tracks near the ends of the deer guards and when no crossings occurred. At least one animal on each day was interpreted as having been prevented from crossing over the guard. 


\section{Results and Discussion}

\section{Controlled Conditions}

Sixteen of the 18 test deer crossed the structures (Table 1). The mean $( \pm S)$ time from release to crossing was $172.6( \pm$ 274) seconds. The range of 11 to 1017 seconds was indicative of the variable responses observed (Fig. 2).

One question that prompted the study was how far would deer jump to clear guards. During our observations no deer seriously attempted to jump even the shortest guard $(12 \mathrm{ft})$. The distance covered by each animal's first step or bound onto the guard averaged $4.56( \pm$ 2.1) $\mathrm{ft}$ with a maximum of $7.94 \mathrm{ft}$ (Table 1). Although deer may be capable of running broad jumps of almost $30 \mathrm{ft}$ (Severinghaus and Cheatum, 1956), they did not use this ability to cross barriers of the type tested.

Four of the 14 deer that crossed the 12- and 18 -ft guards fell through the steel railings with all four legs. None of these animals were seriously injured. Their predominant response was to roll onto their sides, thereby getting their hooves onto the rails again. Apparently the dew claws prevented the animals from falling through more frequently (Fig. 3).

\section{Field Conditions}

As determined by track counts, four deer crossed the Avon guard between October 6 and December 31, 1972. Eleven deer and one elk crossed the Trail Gulch guard from June 29, 1972, to April 19,1973 (Table 2). None of these animals jumped even the shortest guard (12 $\mathrm{ft}$ ). The tracks counted adjacent to the guards were probably not indicative of deer numbers present since one deer may make many tracks. However, tracks recorded without crossings represent at

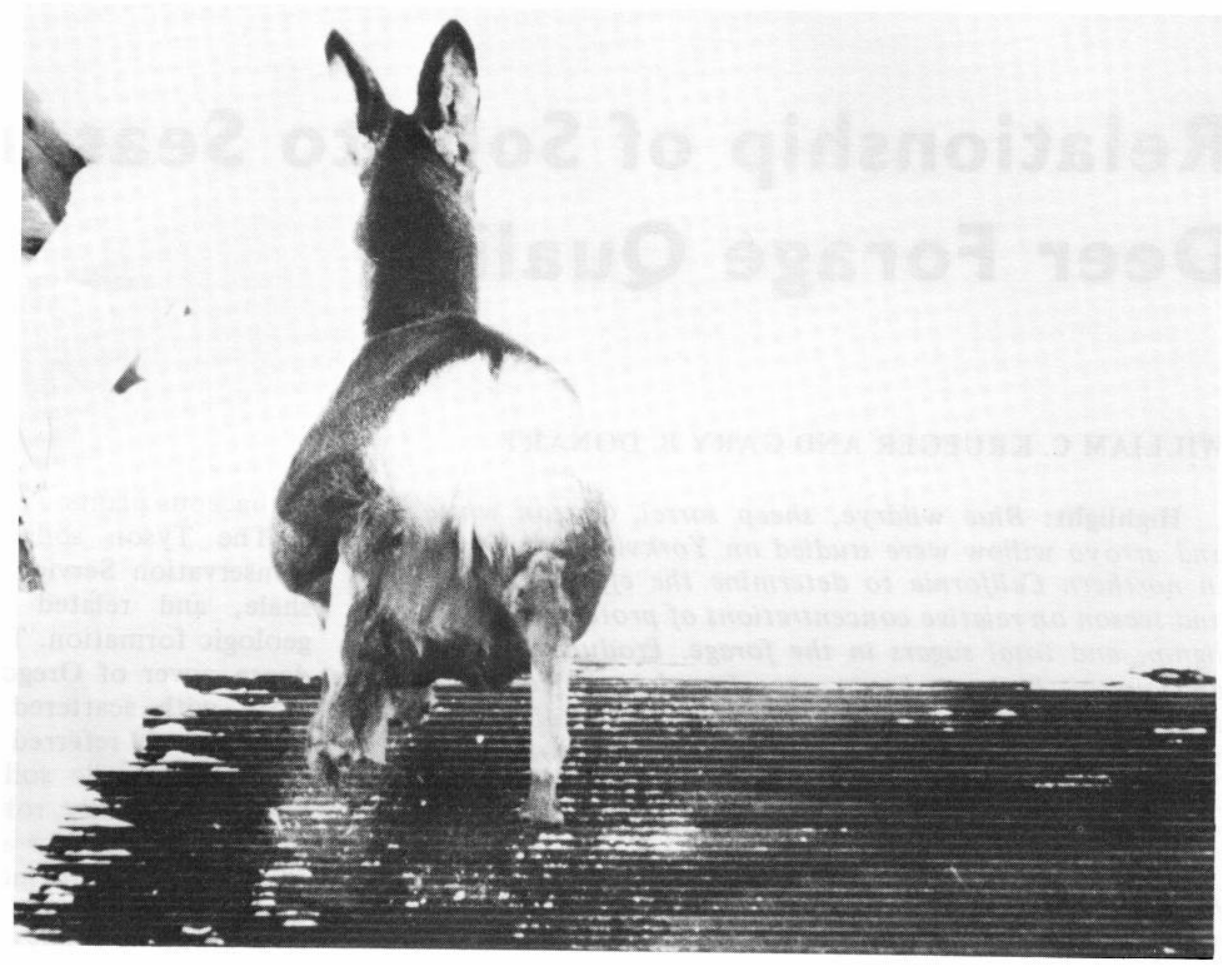

Fig. 3. Dew claws may have prevented this deer from slipping into the guard. The dew claws on the right back leg appear to be spread and in contact with one of the guard rails.

least the presence of one deer each time it was checked, a total of which indicates a minimum number of crossings prevented (Table 2).

\section{Conclusions}

Study results demonstrate that this modified deer-cattle guard had limited effectiveness in preventing deer movements through openings in 8 -ft fences. Deer did not attempt extensive jumps of 12-, 18-, or 24-ft guards when moderately to highly motivated, but rather walked, trotted, or bounded across them. Little advantage was gained by extending the length of the guard beyond $12 \mathrm{ft}$. The use of modified deer-cattle guards (of the type used in this study) for precluding deer movements through openings in 8 - $\mathrm{ft}$ fences should be avoided.

\section{Literature Cited}

Bartmann, R. M., and S. F. Steinert. 1970. A carrying crate for deer. Colo. Div. Game, Fish and Parks. Game Inform. Leafl. No. 79 p. 2.

Scott, J. P. 1956. The analysis of social organization in animals. Ecology 37:213-220.

Severinghaus, C. W., and E. L. Cheatum. 1956. The deer of North America. Stackpole, Harrisburg, Pa., and Wildlife Manage. Inst., Washington, D. C. 161 p.

\section{ㅁㅁㅁㅁ}

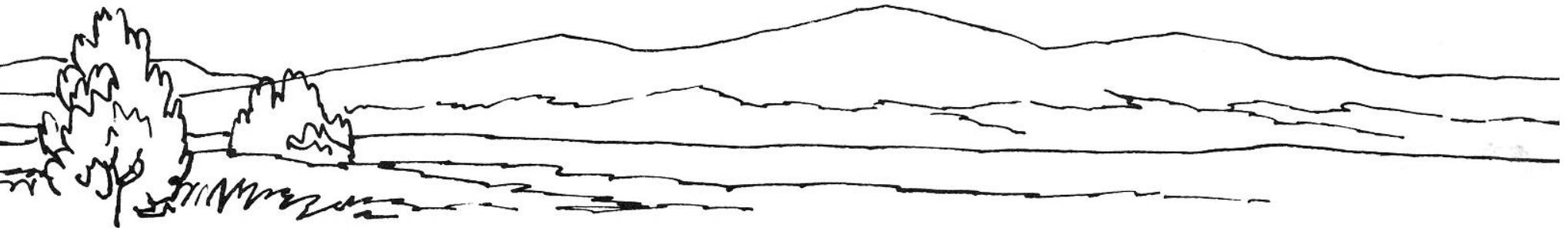

